\title{
PENGARUH SERVICE ENCOUNTER DAN EXPERIENTAL VALUE TERHADAP CUSTOMER SATISFACTION (STUDI KASUS MATAHARI DEPARTMENT STORE MATOS MALANG)
}

JURNAL

Nuri purwanto MANAJEMEN

INDONESIA

STIE PGRI Dewantara Jombang

nuri.stiedw@yahoo.com

Vol.18 No.1

Abstrak

April 2018

Tujuan penelitian ini adalah untuk mengetahui dan menganalisis pengaruh service encounter terhadap experiental value, serta pengaruh experiental value terhadap customer satisfaction. Responden adalah 115 orang yang pernah melakukan transaksi pembelian di Matahari Department store MATOS Malang minimal 1 kali dalam 1 bulan. Teknik pengambilan sampel mengunakan purposive sampling dan metode analisia data menggunakan Teknik Structural Equation Model. Hasil penelitian ini menemukan: Dari hasil pembahasan yang tertulis di atas, dapat ditarik beberapa kesimpulan yaitu : Personal Interaction Encounters berpengaruh positif dan signifikan terhadap Efficiency, Personal Interaction Encounters berpengaruh positif dan signifikan terhadap Service Excellence, Physical Environment Encounters berpengaruh negatif dan tidak signifikan terhadap Aesthetic, Physical Environment Encounters berpengaruh positif dan signifikan terhdap Playfulnes, Efficiency berpengaruh negatif dan tidak signifikan terhadap Customer Satisfaction, Service Excellence berpengaruh positif dan signifikan terhadap Customer Satisfaction, Aesthetic berpengaruh negatif dan tidak signifikan terhadap Customer Satisfaction dan yang terakhir Playfulnes berpengaruh positif dan tidak signifikan terhadap Customer Satisfaction.

Kata kunci: service encounter, experiental value, Customer Satisfaction

\section{Abstract}

The objective of this research is to know and to analyze the impact of service encounter toward experiential value and the impact of value toward Customer Satisfaction. The respondents are 115 people who have ever do transaction in Matahari department store MATOS Malang. The sampling technique is by using purposive sampling and the data analysis is structural equation model. This research finds that Personal Interaction Encounters has positive and significant impact to Efficiency, Personal Interaction Encounters has positive and significant impact toward service excellent, Physical Environment Encounters has negative impact and insignificant toward aesthetic, Physical Environment Encounters has positive and significant impact toward Playfulness, Efficiency has negative and insignificant impact toward Customer Satisfaction, service excellent has positive and significant impact toward Customer Satisfaction, aesthetic has negative impact and insignificant in Customer Satisfaction, and the last Playfulness has negative impact and insignificant toward Customer Satisfaction.

Keywords: service encounter, experiental value, Customer Satisfaction 


\section{Pendahuluan}

Perkembangan bisnis ritel di Indonesia bisa dikatakan sangat mengembirakan, hal tersebut terbukti dengan meningkatnya gerai ritel di Indonesia sebesar 17, $5 \%$ tiap tahunya, dari jumlah ritel sebanyak 10.365 gerai pada tahun 2007 beranjak naik menjadi 18.152 pada tahun 2011(Noor, 2016). Ritel merupakan industri yang menjual produk dan jasa pelayanan, yang telah diberi nilai tambah untuk memenuhi kebutuhan pribadi, keluarga, kelompok atau pemakai akhir (Soliha, 2008). Industri ritel dapat dibedakan dari tingkat harga dan biaya produk yang dikenakan (Utami, 2010), yaitu: (a) toko diskon, menyediakan berbagai produk dengan tingkat harga yang lebih rendah serta serta layanan yang lebih terbatas, (b) Departement Store, menetapkan tingkat harga yang lebih tinggi karena menanggung biaya yang lebih tinggi dalam persediaan beberapa produk fashionable, serta terdapat layanan penjualan perseorangan (personal sales) dan memiliki lokasi toko yang bagus. Departement Store adalah salah satu jenis ritel yang menjual variasi produk yang luas dan berbagai jenis produk dengan menggunakan beberapa staf, seperti layanan pelangan dan tenaga sales counter (Utami, 2010). PT. Matahari Department store merupakan salah satu perusahaan ritel dengan format departement store yang ikut meramaikan dunia bisnsi ritel dan turut mendulang kesuksesan terbukti dengan hasil laba bersih yang diperolehnya. Pada tahun 2016 semester pertama laba bersih yang diperoleh oleh PT. Matahari Department store tercatat sebesar Rp. 5,7 miliar, naik lebih tinggi sebesar 10,8 persen bila dibdaningkan pada semester satu tahun 2016 yang hanya mampu meraih angka laba bersih sebesar 5,1 miliar (Hartanto, 2017).

Malang merupakan salah satu kota fashion, oleh karena itu banyak sekali masyarakat yang membeli produk fashion di boutiqe, factory outlet dan Department store salah satu Department store yang banyak dikunjungi adalah Matahari Department store yang terletak di Mall Malang Town Square (MATOS), Matahari Department store dipilih sebagai tujuan berbelanja karena terkenal dengan kemegahanya (Hag et al., 2016). Oleh karena itu banyak sekali pengunjung yang membeli produk fashion di Matahari Department store MATOS. Kenyamanan berbelanja, serta produk yang lengkap dan kemudahan melakukan transaksi merupakan salah satu alasan kenapa masyarakat lebih memilih untuk berbelanja di ritel modern yaitu Departement store (Amalia, 2010). Namun, sejalan dengan pertumbuhan ritel yang semakin pesat, berdampak pada tingkat persaingan yang semakin tajam sehingga perusahaan diharuskan untuk menciptakan strategi agar mampu bersaing dan memenangkan pasar. Persaingan bisnis retail telah nampak dengan adanya direct distribution channels seperti tv kabel, catalogs dan internet (Keng et al., 2007), bila dihubungakan dengan internet maka hal tersebut merujuk pada praktek e-commerce. Definisi e-commerce menurut Haryati dan Tjendrowaseno (2012) merupakan cara seorang konsumen untuk dapat membeli barang yang diinginkan secara online. Negara Indonesia merupakan negara dengan jumlah pengadopsi teknologi e-commerce dan mobile commerce yang signifikan di Asia Pasifik, khususnya Business to Consumer. Kenyataan tersebut merupakan suatu fenomena yang harus di waspadai oleh para pengusaha di bidang ritel, khususnya ritel secara off-line (Tjahyana, 2015). Kemudahan berbelanja tanpa perlu datang ke toko, transaki dengan metode COD (Cash On Delivery), kemudahan dalam pengiriman merupakan alasan kenapa memilih berbelanja secara online (Priansa, 2016).

Salah satu cara agar mampu memenangkan persaingan pasar adalah dengan memberikan kepuasan kepada konsumen. Sekali konsumen puas dengan pelayanan atau dengan produk yang diberikan oleh perusahaan, maka mereka akan cenderung untuk kembali membeli produk yang ditawarkan atau datang ke toko, dan hal tersebut dapat meningkatkan keuntungan perusahaan (Heskett et al., 2008). Kepuasan didefinisikan sebagai penyampaian seorang konsumen terhadap penampilan produk yang telah didapatkan yang erat kaitanya dengan harapan dari konsumen (Kotler dan Armstrong, 2012). Menciptakan suatu customer satisfaction tidaklah mudah, hal tersebut dikarenakan kebutuhan dan keinginan konsumen selalu mengalami perubahan dari waktu ke waktu (Semuel, 2006). Maka tidaklah heran beberapa peneliti mencoba mencari jawaban, mengenai berbagai macam perspektif tentang bagaimana suatu kepuasan dapat dibangun (Sulek dan Hensley, 2004).

Jika retailers berharap untuk mendapatkan konsumen yang puas dan loyal, maka mereka harus menawarkan pelayanan yang berkualitas tinggi (Verhagen et al., 2011). Customer service encounters didefinisikan sebagai kesan pertama yang diterima oleh konsumen saat

Jurnal Manajemen Indonesia 
pertama kali menghadapi produk, pelayanan atau perusahaan, dimana kesan tersebut akan dibawa dan dikomunikasikan dengan orang lain (Poulsson dan Kale, 2004). Service encounter bermanfaat untuk memberikan informasi dasar dari konsumen mengenai customer preference, dan pihak perusahaan dapat memanfaatkan informasi tersebut untuk meningkatkan pelayanan mereka (Shieh dan Ming-Sung, 2007). Service encounter merupakan suatu proses dimana konsumen mengevaluasi tingkat layanan yang disediakan oleh perusahaan, layanan personel dan bahkan interaksi dengan konsumen lain dalam kurun waktu tertentu (Bitner, 1990). Berbicara mengenai interaksi dengan konsumen lain, menurut (Cox et al., 2005) dalam teori experiental value menyebutkan bahwa konsumen membentuk nilai pengalaman mereka melalui interaksi baik secara langsung maupun tidak langsung dengan produk atau jasa yang disedikan oleh perusahaan. Service encounter dan experiental value keduanya dibentuk oleh persepsi konsumen mengenai penyedia layanan (Keng et al., 2007) walaupun experiental value dan service encounter telah diteliti secara terpisah di beberapa penelitian, namun keduanya belum pernah diteliti secara bersamaan dalam konteks bisnis retail (Keng et al., 2007).

Berdasarkan latar belakang masalah diatas, masalah yang akan diselesaikan dapat dirumuskan sebagai berikut: (1) Apakah terdapat pengaruh dimensi personal interaction encounters, physical enviromental encounters dari variabel service encounter terhadap dimensi experiental value yang terdiri dari efficiency, excellent service, aesthetics dan playfulness. (2) Apakah terdapat pengaruh langsung dari dimensi experiental value yaitu eEfficiency, excellent service, aesthetics dan playfulness terhadap customer satisfaction.

\section{Landasan Teori dan Metodologi}

\subsection{Service encounter}

Membuat service encounter yang lebih menyenangkan dapat mengurangi resiko yang diraskan terkait dengan layanan yang dirasakan ketika membeli suatu produk atau jasa dan hal tersebut akan meningkatkan pengalaman dalam berbelanja (Julian dan Ramaseshan, 1994). Dimensi dari service encounter banyak diteliti oleh para peneliti di bidang pemasaran jasa dimensi dari service encounter dapat dibagi menjadi dua component seperti yang tertulis sebagai berikut ( Keng et al., 2007): dimensi yang pertama disebut sebagai personal interaction encounter, dipandang sebagai periode dimana konsumen berinteraksi dengan tenaga pelayanan, sedangkan kualitas interaksi dengan tenaga pelayanan dapat dilihat dari kompentensi tenaga pelayanan seperti, kemampuan untuk mendengar keluhan konsumendan tingkat pelayanan ( Wu dan Liang, 2009). Personal service encounter menyangkut berbagai hal yang disediakan oleh penyedia jasa dalam bentuk suatu layanan yang dilakukan oleh tenaga pelayanan untuk melayani segala kebutuhan konsumen, karena interaksai antara tenaga pelayanan dengan konsumen merupakan fase yang sangat penting dalam proses evaluasi konsumen mengenai keseluruahan pelayanan yang diberikan oleh perusahaan yaitu Matahari Department store MATOS Malang, hal tersebut sangat penting karena menurut penelitian yang dilakukan oleh (Wu dan Liang, 2009) perilaku tertentu yang spesifik salah satunya adalah pelayanan yang dilakukan oleh tenaga pelayanan kepada konsumen merupakan faktor yang penting dalam mempengaruhi aspek kualitas pelayanan dan kepuasan pelanggan. Dimensi kedua dari variabel service encounter adalah environmental elements atau bisa juga disebut sebagai physical environment, didefinisikan sebagai periode dimana konsumen berinteraksi dengan fasilitas fisik dan element tangible lainya dalam lingkungan layanan tersebut seperti (pencahayaan, musik dan design dalam maupun luar ruangan (Wu dan Liang, 2009). Dalam penelitian yang dilakukan oleh (Keng et al., 2007) membuktikan ada hubungan positif antara dimensi service ecounter yaitu personal interaction encounter dan physical environment terhadap experiental value.

$\mathrm{H}_{1}$ : Diduga terdapat pengaruh positif Personal Interaction Encounters terhadap Efficiency

$\mathrm{H}_{2}$ : Diduga terdapat pengaruh positif Personal Interaction Encounters terhadap Service Excellence

$\mathrm{H}_{3}$ : Diduga terdapat pengaruh positif physical environment terhadap Aesthetic 
JURNAL

MANAJEMEN

INDONESIA

Vol.18 No.1

April 2018

\subsection{Experiental Value}

Experiental value, difenisikan sebagai penilaian konsumen mengenai efisiensi pelayanan, keungulan layanan, keindahan dan kegembiraan dalam service encounters (Wu dan Liang, 2009). Mathwick et al. (2002) mengunakan empat dimensi untuk mengukur experiental value yang dinamakan dengan Experiental Value Scale atau dapat disingkat menjadi (EVS) adapun dimensi tersebut adalah: (1) Efficiency value, mencerminkan aspek utilitarian dari berbelanja, serta mendiskripsikan investasi aktif dalam ekonomi, waktu, sumber perilaku dan psikologi yang mengakibatkan pengembalian yang positif. Untuk memahami dimensi tersebut dapat dicontohkan sebagai berikut, sebagai seorang konsumen kita menyadari bahwa dalam berbelanja di suatu pusat perbelanjaan kita mengeluarkan suatu usaha yaitu : waktu untuk menunggu antrian, tenaga yang kita keluarkan untuk mencari produk yang kita inginkan, uang yang kita keluarkan untuk membayar parkir, untuk membeli produk yang kita inginkan dan uang yang diberikan kepada pelayan untuk mengangkut barang kita sampai ke kendaraan kita dan lain sebagainya; (2) Service Excellence dan aesthetic dipdanang oleh konsumen sebagai sisi reaktif dari customer experience. Dan aesthetic value yang dirasakan merupakan reaksi terhadap harmoni dan kesatuan benda fisik, irama, atau kinerja (Veryzer Jr, 1993).

Dalam suatu industri retailing dimensi aesthetic dapat terlihat dari daya tarik visual yang terlihat dari design tata ruang serta daya tarik fisik bangunan dari pusat perbelanjaan tersebut. (3) Service excellence value, mengambarkan kinerja dari produk dan umumnya di apresiasi konsumen dari penyedia jasa atau layanan yang telah membuktikan keunggulan kinerja pelayananya yang telah mereka rasakan. (4) Perceived Playfulness, yang diciptakan oleh konsumen itu sendiri, hal tersebut terjadi dalam diri konsumen, suatu inisiatif dan pengalaman yang berorientasi pada pribadi masing-masing konsumen. Banyak literature yang relevant yang memuat berbagai pdanangan mengenai experiental value, namun penelitian mengenai hubungan antara expereintal value terhadap customer satisfactio masih jarang sekali dilakukan (Wu dan Liang, 2009). Terlebih lagi bahwa konsumen saat ini tidak hanya membeli suatu produk ataupun jasa namun juga mencari suatu nilai, beberapa literature mengenai retailing menekankan mengenai pentingnya menciptakan suatu experiental value dan bagaimana seorang pemasar dalam bisnis retail harus bertindak menyikapi fenomena tersebut(Keng et al., 2007) Dari hasil penelitian yang dilakukan oleh (Chen dan Hsieh, 2010) menunjukan hasil bahwa variabel experiental value berpengaruh terhadap variabel Customer Satisfaction.

$\mathrm{H}_{5}$ : Diduga terdapat pengaruh positif Efficiency terhadap Customer Satisfaction

$\mathrm{H}_{6}$ : Diduga terdapat pengaruh positif Service Excellencec terhadap Customer Satisfaction

$\mathrm{H}_{7}$ : Diduga terdapat pengaruh positif Aesthetic terhadap Customer Satisfaction

$\mathrm{H}_{8}$ : Diduga terdapat pengaruh positif Playfulnes terhadap Customer Satisfaction

\subsection{Costumer Satisfaction}

Customer Satisfaction, adalah perasaan senang atau kecewa seseorang yang muncul setelah membdaningkan antara persepsi/kesannya terhadap kinerja (atau hasil) suatu produk dan harapan-harapannya ((Kotler dan Armstrong, 2012)). Dari hasil penelitian yang dilakukan oleh (Gibson, 2005) menyatakan bahwa konsumen yang puas akan suatu produk atau jasa yang telah dikonsumsi akan kembali menggunakan atau mengkonsumsi produk atau jasa tersebut serta akan memberikan umpan balik yang positif kepada keluarga dan teman mengenai pengalaman konsumen mengkonsumsi produk atau jasa tersebut sehingga dapat menarik pembeli baru. Apabila seorang pebisnis paham dan mengerti faktor-faktor yang mampu membuat konsumen menjadi puas akan suatu produk atau jasa yang ditawarkan akan membuat perusahaan tersebut mampu untuk menciptkan dan mengantarkan penawaran yang pantas dan lebih baik dari pesaing sehingga tawaran yang kita berikan akan disambut dengan baik serta akan memicu adanya suatu permintaan pasar. Menyadari pentingnya analisis Customer Satisfaction sangatlah penting, dengan modal pengetahuan tersebut mungkin dapat memperbaiki pengalaman konsumen dengan produk atau layanan sehingga konsumen akan

\section{Jurnal Manajemen Indonesia}


merasakan kepuasan maksimal (Petrick et al., 2001). Berdasarkan uraian teori yang telah dikemukakan di atas maka kerangka konseptual penelitian dapat digambarkan sebagai berikut:

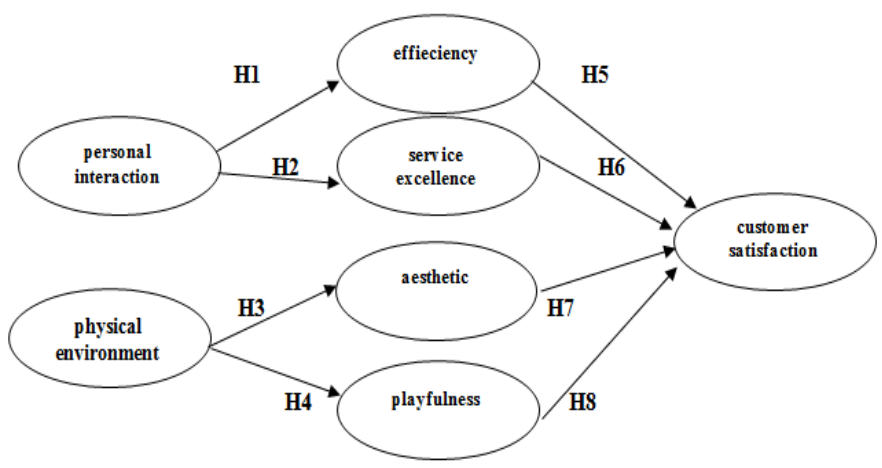

JURNAL

MANAJEMEN

INDONESIA

Vol.18 No.1

April 2018

Gambar 1

Skema Kerangka Konseptual

\section{Metode Penelitian}

\subsection{Desain Penelitian}

Rancangan Penelitian. Penelitian ini mengacu pada penelitian sebelumnya yang dilakukan oleh (Keng et al., 2007, Chen dan Hsieh, 2010) dan (Wu dan Liang, 2009). Rancangan penelitian yang digunakan adalah Hypothesis Testing. Variabel yang digunakan dalam penelitian ini terdiri dari tiga variabel, yaitu : (1) Service encounter, (2) Experiental value, (3) Customer Satisfaction. Seluruh variabel diukur dengan menggunakan sejumlah dimensi dan item pernyataan yang diukur menggunakan Skala Likert dengan pengukuran angka satu hingga lima; dimana $1=$ sangat tidak setuju, 2 = tidak setuju, $3=$ cukup setuju, $4=$ setuju, 5 = sangat setuju.

\subsection{Populasi dan Sampel Penelitian}

Populasi adalah adalah gabungan dari seluruh elemen yang bebentuk peristiwa, hal atau orang yang memiliki karakteristik yang serupa yang menjadi pusat perhatian seoerang peneliti (Agusty, 2006) populasi penelitian ini adalah konsumen yang pernah berbelanja di Matahari Department store MATOS Malang. Dalam penelitian ini teknik pengambilan sampel yang digunakan adalah non-probability sampling dengan teknik pengambilan. Sampel purposive sampling, pada teknik ini peneliti memilih sampel purosive atau sampel bertujuan secara subyektif (Agusty, 2006), menurut (Agusty, 2006) model SEM yang sensitif terhadap jumlah sampel, dibutuhkan sampel yang baik berkisar antara 100-200 sampel. Sebagai cadangan apabila ada jawaban kuesioner yang kurang valid atau kuesioner tidak kembali, maka diambil sampel sebanyak 115 .

\subsection{Teknik Pengumpulan Data}

Data penelitian ini merupakan data primer yaitu data yang dikumpulkan secara langsung oleh peneliti melalui penyebaran kuesioner, sedangkan kuesioner dibagai menjadi dua bagian, pada bagian pertama berisi mengenai demografi dan profil responden sedangkan pada bagian kedua bersisi pernyataan untuk mengukur atribut-atribut yang sedang diteliti

\subsection{Metode Analisis Data}

Metode Analisa Data. Teknik analisa data yang digunakan dalam penelitian menggunakan Structural Equation Modeling (SEM) dengan software GeSca (Generalized Structured Component Analysis). Pada analisis GeSca measure of fit dapat dilakukan pada 
model pengukuran, model struktural, dan model keseluruhan (overall Model ) (Ghozali, 2008).

JURNAL

MANAJEMEN

INDONESIA

Vol.18 No.1

April 2018

\section{Hasil dan Pembahasan}

\subsection{Hasil Penelitian}

Dari seluruh data responden dapat ditarik kesimpulan bahwa mayoritas responden berusia 21- 24 tahun, jenis kelamin adalah perempuan, sedangkan bila dilihat dari tingkat pendidikan rata - rata adalah mahsiswa S1, dengan penghasilan berkisar antara Rp. 500.000 sampai Rp. 700.000 sedangkan minoritas responden adalah berusia 27 sampai 30 tahun dengan jenis kelamin pria, tingkat pendidikan adalah pascasarjana dan berpenghasilan diatas Rp. 300.000 - Rp 500.000. rata-rata berbelanja di Matahari Department store lebih dari atau sama dengan tiga kali tiap bulan.

\subsection{Evaluasi Model Pengukuran}

Dalam penelitian ini menggunakan model pengukuran reflektif, sedangkan measure of fit pada model pengukuran reflektif indicator dinilai berdasarkan nilai loading factor masing masing indicator pembentuk konstruk laten, Suatu indikator dikatakan valid apabila loading factor suatu indikator bernilai positif dan lebih besar 0.6, sedangkan reabilitas yang baik jika nilai Cronbach Alpha $\geq 0,70$ dan nilai AVE $\geq 0,50$ (Ghozali, 2008), data yang termuat dalam tabel 3 berikut ini menampilkan hasil dari measure of fit dari variabel penelitian yang digunakan, untuk menguji validitas menggunakan convergent validity sedangkan untuk reliabelitas menggunakan discriminant validity adapun hasil dari pengujian tersebut dapat dijelaskan sebagai berikut. Convergent Validity dimaksudkan untuk mengetahui valid tidaknya indikator dalam mengukur variabel. Convergent validity setiap indikator dalam mengukur variabel ditunjukkan oleh besar kecilnya loading factor. Suatu indikator dikatakan valid apabila loading factor suatu indikator bernilai positif dan lebih besar 0.6. Hasil pengujian convergent validity dapat terlihat melalui tabel yang tersaji pada tabel di bawah ini

\begin{tabular}{lccccc}
\hline \multirow{1}{*}{ Variable } & Indikator & \multicolumn{3}{c}{ Loadings Factor } & \multirow{2}{*}{ Keterangan } \\
& & Estimate & SE & CR & \\
Personal & PI & 0.757 & 0.07 & $10.86^{*}$ & Valid \\
$\begin{array}{l}\text { Enteraction } \\
\text { Encounters }\end{array}$ & PI2 & 0.636 & 0.092 & $6.93^{*}$ & Valid \\
& PI3 & 0.637 & 0.105 & $6.05^{*}$ & Valid \\
& PI4 & 0.746 & 0.059 & $12.62^{*}$ & Valid \\
& PI5 & 0.755 & 0.062 & $12.1^{*}$ & Valid \\
Physical & PEvironment & 0.848 & 0.036 & $23.53^{*}$ & Valid \\
Encounters & PE2 & 0.765 & 0.056 & $13.78^{*}$ & Valid \\
& PE3 & 0.835 & 0.052 & $16.01^{*}$ & Valid \\
& PE4 & 0.796 & 0.062 & $12.8^{*}$ & Valid \\
Efficiency & PE5 & 0.812 & 0.036 & $22.65^{*}$ & Valid \\
& EF1 & 0.752 & 0.061 & $12.37^{*}$ & Valid \\
& EF2 & 0.889 & 0.024 & $36.37^{*}$ & Valid \\
& EF3 & 0.737 & 0.087 & $8.48^{*}$ & Valid \\
\hline
\end{tabular}

Tabel 1.

Pengukuran Convergent Validity

Sumber: output GeSCA diolah (2018) 


\begin{tabular}{lccccc}
\hline \multirow{2}{*}{ Variable } & Indikator & \multicolumn{3}{c}{ Loadings Factor } & \multirow{2}{*}{ Keterangan } \\
& & Estimate & SE & CR & \\
Service Excelencece & SE2 & 0.761 & 0.048 & $15.8^{*}$ & Valid \\
& SE3 & 0.832 & 0.041 & $20.12^{*}$ & Valid \\
& AE1 & 0.772 & 0.068 & $10.91^{*}$ & Valid \\
Aesthetic & AE2 & 0.837 & 0.056 & $13.89^{*}$ & Valid \\
& AE3 & 0.685 & 0.088 & $7.8^{*}$ & Valid \\
& PL1 & 0.834 & 0.044 & $18.83^{*}$ & Valid \\
Playfulness & PL2 & 0.815 & 0.068 & $11.99^{*}$ & Valid \\
& PL3 & 0.83 & 0.044 & $18.84^{*}$ & Valid \\
Customer & CS1 & 0.902 & 0.027 & $33.6^{*}$ & Valid \\
Satisfaction & CS2 & 0.871 & 0.043 & $20.47^{*}$ & Valid \\
\hline
\end{tabular}

JURNAL

MANAJEMEN

INDONESIA

Vol.18 No.1

April 2018

Berdasarkan hasil analisis model pengukuran dapat diketahui bahwa semua indikator yang mengukur variabel Personal Interaction Encounters, Physical Environment Encounters, Efficiency, Service Excellence, aesthetic, Playfulness, dan Customer Satisfaction menghasilkan loading factor yang lebih besar dari 0.6. Dengan demikian indikator yang mengukur variabel Personal Interaction Encounters, Physical Environment Encounters, Efficiency, Service Excellence, aesthetic, Playfulness, dan Customer Satisfaction dapat dinyatakan valid atau mampu mengukur variabel tersebut.

Discriminant Validity setiap indikator dalam mengukur dimensi ditunjukkan oleh akar dari Average Variance Extracted (AVE). Suatu indikator dikatakan memiliki discriminant validity apabila akar dari $A V E$ bernilai lebih besar dari korelasi antar konstruk. Hasil pengujian discriminant validity dapat dilihat melalui tabel dibawah ini :

\begin{tabular}{llllllll}
\hline & PI & PE & EF & SE & AE & PL & CS \\
\hline personal interaction & $\mathbf{0 . 7 0 9}$ & 0.65 & 0.587 & 0.383 & 0.055 & 0.593 & 0.635 \\
\hline physical environment encounters & 0.65 & $\mathbf{0 . 8 1 2}$ & 0.68 & 0.323 & -0.09 & 0.543 & 0.51 \\
\hline Efficiency & 0.587 & 0.68 & $\mathbf{0 . 7 9 6}$ & 0.456 & 0.055 & 0.547 & 0.438 \\
\hline Service Excellence & 0.383 & 0.323 & 0.456 & $\mathbf{0 . 7 7 9}$ & 0.558 & 0.408 & 0.384 \\
\hline aesthetic & 0.055 & -0.09 & 0.055 & 0.558 & $\mathbf{0 . 7 6 7}$ & 0.299 & 0.148 \\
\hline Playfulness & 0.593 & 0.543 & 0.547 & 0.408 & 0.299 & $\mathbf{0 . 8 2 6}$ & 0.701 \\
\hline costumer satisfaction & 0.635 & 0.51 & 0.438 & 0.384 & 0.148 & 0.701 & $\mathbf{0 . 8 8 7}$ \\
\hline
\end{tabular}

Tabel 2.

Pengukuran Convergent Validity

Sumber :

output GeSCA diolah (2018)

Hasil analisis yang tertera pada tabel diatas dapat diketahui bahwa nilai dari akar AVE pada masing-masing variabel lebih besar daripada koefisien korelasi antar variabel. Dengan demikian discriminant validity semua indikator yang digunakan dalam penelitian mengukur variabel Personal Interaction Encounters, physical environment encounters, Efficiency, Service Excellence, aesthetic, Playfulness, dan Customer Satisfactiondinyatakan terpenuhi. Goodness of fit model dimaksudkan untuk mengetahui apakah konstruk yang terbentuk telah sesuai (layak) atau tidak. Indeks goodness of fit dalam analisis GSCA, yaitu Fit, AFit, GFI, dan SRMR. Kriteria menggunakan GFI menyebutkan apabila nilai GFI $\geq$ nilai cut off (sebesar 0.90) maka model dinyatakan good fit (layak), sementara apabila nilai GFI berada di dalam rentang 0.8 - 0.9 maka model dinyatakan marginal fit (cukup layak). Sementara nilai FIT 
menunjukkan seberapa besar variabel eksogen mampu menjelaskan variabel endogennya. Hasil goodness of fit model dapat dijelaskan sebagai berikut: global optimalization GFI sebesar 0.988. Hal ini menunjukkan GFI > 0.9. Dengan demikian model GSCA secara keseluruhan terhadap Customer Satisfaction dinyatakan good fit (layak). Nilai kecocokan sebesar 0.523 menunjukkan kontribusi variabel Personal Interaction Encounters, Physical Environment Encounters, Efficiency, Service Excellence, aesthetic, dan Playfulness secara keseluruhan terhadap Customer Satisfaction sebesar 52.3\%. Sedangkan sisanya sebesar 48.7\% merupakan kontribusi variabel lain yang tidak tidak dibahas dalam penelitian.

\subsection{Hasil Uji Hipotesis}

Pengujian hipotesis dimaksudkan untuk menguji ada tidaknya pengaruh variabel eksogen secara langsung terhadap variabel endogen. Pengujian hipotesis dapat diketahui melalui nilai critical ratio (CR). Kriteria pengujian menyebutkan bahwa apabila koefisien jalur bernilai positif dan critical ratio $(\mathrm{CR})$ bertdana bintang atau critical ratio $(\mathrm{CR}) \geq \mathrm{t}$-tabel $(\mathrm{t}=2.00$, alpha $=5 \%)$ maka dinyatakan terdapat pengaruh positif dan signifikan variabel eksogen terhadap variabel endogen (Ghozali, 2008). Pada tabel 5 dapat kita ketahui hasil ringkasan hubungan antara variabel eksogen dengan variabel endogen.

\begin{tabular}{cccc}
\hline & Estimate & SE & CR \\
\hline Personal Interaction Encounters-> Efficiency & 0.587 & 0.074 & $7.94^{*}$ \\
\hline Personal Interaction Encounters-> Service Excellence & 0.383 & 0.081 & $4.74^{*}$ \\
\hline Physical Environment Encounters->Aesthetic & -0.090 & 0.126 & 0.72 \\
\hline Physical Environment Encounters $>$ Playfulnes & 0.543 & 0.099 & $5.47^{*}$ \\
\hline Efficiency->Customer Satisfaction & -0.020 & 0.127 & 0.16 \\
\hline Service Excellence->Customer Satisfaction & 0.214 & 0.106 & $2.02^{*}$ \\
\hline Aesthetic $->$ Customer Satisfaction & -0.174 & 0.088 & 1.97 \\
\hline Playfulnes $>$ Customer Satisfaction & 0.677 & 0.097 & $6.95^{*}$ \\
\hline
\end{tabular}

\subsubsection{Pengaruh Personal Interaction Encounters terhadap Efficiency}

Menyatakan pengaruh Personal Interaction Encounters terhadap Efficiency menghasilkan koefisien jalur sebesar 0.587 dengan critical ratio (CR) sebesar 7.94* (bertdana bintang). Hal ini berarti koefisien bernilai positif dan nilai $\mathrm{CR}>\mathrm{t}$-tabel $(\mathrm{t}=2.00$, alpha $=5 \%)$ ). Oleh karena itu, dapat diartikan bahwa terdapat pengaruh positif dan signifikan Personal Interaction Encounters terhadap Efficiency. Dengan demikian hipotesis 1 terpenuhi. Hasil temuan dalam penelitin ini sejalan dengan penelitian yang dikemukakan oleh (Keng et al., 2007) yang mengemukakan bahwa Personal Interaction Encounters berpengaruh positif terhadap efisiensi dan excellence value, serta didukung oleh hasil penelitian (Wu dan Liang, 2009). Hasil empiris menunjukkan bahwa faktor lingkungan restoran dan interaksi dengan karyawan pada bagian layanan dan interaksi antar konsumen lainnya mempengaruhi secara positif dari experiental value.

\subsubsection{Pengaruh Personal Interaction Encounters terhadap Service Excellence}

Menyatakan pengaruh Personal Interaction Encounters terhadap Service Excellence menghasilkan koefisien jalur sebesar 0.383 dengan critical ratio (CR) sebesar $4.74^{*}$ (bertdana bintang). Hal ini berarti koefisien bernilai positif dan nilai $\mathrm{CR}>\mathrm{t}$-tabel $(\mathrm{t}=2.00$, alpha $=5 \%)$ ). Oleh karena itu, dapat diartikan bahwa terdapat pengaruh positif dan signifikan Personal Interaction Encounters terhadap Service Excellence. Dengan demikian hipotesis 2 terpenuhi. Penelitian tersebut sejalan dengan penelitan (Dennis et al., 2007) nilai dari experiental value akan meningkat ketika personal interaction encounter dilaksanan dengan baik. (Fitzsimmons dan Fitzsimmons, 2013) menyatakan bahwa encounter yang didominasi oleh personal biasanya terdapat pada suatu kondisi dimana personal dapat mengendalikan konsumen. Kesigapan yang ditunjukan oleh para tenaga pelayanan dalam melayani konsumen, serta

Jurnal Manajemen Indonesia 
masukan saran yang logis ketika berbicara mengenai produk, membuat konsumenmerasa yakin bahwa para tenaga pelayanan telah memberikan pelayanan yang maksimal.

\subsubsection{Pengaruh Physical Environment Encounters terhadap aesthetic}

JURNAL

Menyatakan pengaruh Physical Environment Encounters terhadap aesthetic menghasilkan koefisien jalur sebesar -0.09 dengan critical ratio (CR) sebesar 0.72 (tidak bertdana bintang). Hal ini berarti koefisien bernilai negatif dan nilai $\mathrm{CR}<\mathrm{t}$-tabel $(\mathrm{t}=2.00$, alpha=5\%)). Oleh karena itu, dapat diartikan bahwa terdapat pengaruh negatif dan tidak signifikan Physical Environment Encounters terhadap aesthetic. Dengan demikian hipotesis 3 tidak terpenuhi. Hasil temuan dalam penelitian ternyata tidak sejalan dengan temuan penelitian yang dilakukan oleh (Baker et al., 2002) yang menyatakan ada hubungan positif antara Physical Environment Encounters terhadap experiental value yaitu aesthetic. Hal tersebut terjadi karena hampir semua aspek warna cat dinding, susunan rak pakaian, penataan pencahayaan dirasakan sama antara satu departemnt store dengan department store yang lain, sehingga konsumen tidak merasa ada hal yang cukup istimewa dari model penataan dari departement store tersebut.

\subsubsection{Pengaruh Physical Environment Encounters terhadap Playfulness}

Menyatakan pengaruh Physical Environment Encounters terhadap Playfulness menghasilkan koefisien jalur sebesar 0.543 dengan critical ratio (CR) sebesar 5.47* (bertdana bintang). Hal ini berarti koefisien bernilai positif dan nilai $\mathrm{CR}>\mathrm{t}$-tabel $(\mathrm{t}=2.00$, alpha $=5 \%)$ ). Oleh karena itu, dapat diartikan bahwa terdapat pengaruh positif dan signifikan Physical Environment Encounters terhadap Playfulness. Dengan demikian hipotesis 4 terpenuhi. Temuan tersebut sejalan dengan hasil yang dikemukakan oleh (Ali dan Amin, 2014) yang menyatakan bahwa bahwa konsumenyang memiliki persepsi mengenai Physical Environment Encounters lebih cenderung memiliki emosi positif serta mampu untuk meningkatkan kepuasan konsumen, oleh karena itu sangatlah penting untuk menciptkan Physical Environment Encounters yang bagus sehinga konsumen akan merasa nyaman dan menimbulkan emosi yang positive, karena emosi positif merupakan komponen inti dari Playfulness (Proyer dan Ruch, 2011).

\subsubsection{Pengaruh Efficiency terhadap Customer Satisfaction}

Menunjukan pengaruh Efficiency terhadap Customer Satisfaction menghasilkan koefisien jalur sebesar -0.02 dengan critical ratio (CR) sebesar 0.16 (tidak bertdana bintang). Hal ini berarti koefisien bernilai negatif dan nilai $\mathrm{CR}<\mathrm{t}$-tabel $(\mathrm{t}=2.00$, alpha $=5 \%)$ ). Oleh karena itu, dapat diartikan bahwa terdapat pengaruh negatif dan tidak signifikan Efficiency terhadap Customer Satisfaction. Dengan demikian hipotesis 5 tidak terpenuhi. Hasil tersebut tidak sejalan dengan temuan yang dikemukan oleh (Rosanti, 2014) bahwa experiental value berpengaruh terhadap Customer Satisfaction. Hal tersebut terjadi karena konsumen merasa bahwa berbelanja di matahari departement store merupakan suatu aktivitas yang tidak perlu menjadi suatu aktivitas yang prioritas atau diutamakan, karena mereka merasa ada aktivitas lain yang layak untuk dilakukan daripada hanya sekedar berbelanja menghabiskan uang.

\subsubsection{Pengaruh Service Excellence terhadap Customer Satisfaction}

Pengaruh Service Excellence terhadap Customer Satisfaction menghasilkan koefisien jalur sebesar 0.214 dengan critical ratio (CR) sebesar $2.02^{*}$ (bertdana bintang). Hal ini berarti koefisien bernilai positif dan nilai $\mathrm{CR}>\mathrm{t}$-tabel $(\mathrm{t}=2.00$, alpha=5\%)). Oleh karena itu, dapat diartikan bahwa terdapat pengaruh positif dan signifikan Service Excellence terhadap Customer Satisfaction. Dengan demikian hipotesis 6 terpenuhi. Hasil temuan tersebut sejalan dengan hasil penelitian yang dilakukan oleh (Kurniawati, 2016) yang menyatakan bahwa ada hubungan positif dan signifikan antara Service Excellence terhadap Customer Satisfaction, serta menurut (Sofiyanto et al., 2016) bahwa kualitas layanan sangat menentukan kepuasan konsumen khusunya dalam bidang jasa. 


\subsubsection{Pengaruh aesthetic terhadap Customer Satisfaction}

Pengaruh aesthetic terhadap Customer Satisfaction menghasilkan koefisien jalur sebesar -0.174 dengan critical ratio (CR) sebesar 1.97 (tidak bertdana bintang). Hal ini berarti koefisien bernilai negatif dan nilai $\mathrm{CR}<\mathrm{t}$-tabel $(\mathrm{t}=2.00$, alpha $=5 \%)$. Oleh karena itu, dapat diartikan bahwa terdapat pengaruh negatif dan tidak signifikan Efficiency terhadap Customer Satisfaction. Dengan demikian hipotesis 7 tidak terpenuhi. Hasil tersebut sejalan dengan penelitian (Prabowo, 2016) yang menyatakan bahwa aesthetic tidak mempunyai pengaruh terhadap Customer Satisfaction. Hal tersebut terjadi karena produk yang di jual di departement store merupakan produk fashion yang biasa dimiliki semua orang, bukan produk fashion yang unik seperti distribution store (distro) yang menonjolkan kreativitas desain ataupun butik yang selalu mengikuti perkembangan trend (Kurnia, 2013) serta design ruangan serta pajangan yang stdanar dan hampir sama sehingga membuat konsumen merasa tidak ada sesuatu yang indah yang ditawarkan baik dari sisi produk, layanan maupun ruangan perbelanjaan.

\subsubsection{Pengaruh Playfulnes terhadap Customer Satisfaction}

Pengaruh Playfulnes terhadap Customer Satisfaction menghasilkan koefisien jalur sebesar 0.677 dengan critical ratio (CR) sebesar $6.95^{*}$ (bertdana bintang). Hal ini berarti koefisien bernilai positif dan nilai $\mathrm{CR}>\mathrm{t}$-tabel $(\mathrm{t}=2.00$, alpha $=5 \%)$ ). Oleh karena itu, dapat diartikan bahwa terdapat pengaruh positif dan signifikan Service Excellence terhadap Customer Satisfaction. Dengan demikian hipotesis 8 terpenuhi. Hasil penelitian tersebut sejalan dengan, hasil penelitian ( Astari dan Pramudana, 2016) yang menyatakan ada hubungan antara dimensi Playfulness dengan Customer Satisfaction, suasana ruangan yang nyaman serta keramahan dari para tenaga wiraniaga membuat konsumen merasa betah dan mengangap hal tersebut sebagai aktivitas yang menyenangkan sehingga membuat konsumen nyaman dan merasa betah

\section{Kesimpulan dan Saran}

Dari hasil pembahasan yang tertulis di atas, dapat ditarik beberapa kesimpulan yaitu : (1) Personal Interaction Encounters berpengaruh positif dan signifikan terhadap Efficiency; (2) Personal Interaction Encounters berpengaruh positif dan signifikan terhadap Service Excellence; (3) Physical Environment Encounters berpengaruh negatif dan tidak signifikan terhadap Aesthetic; (4) Physical Environment Encounters berpengaruh positif dan signifikan terhdap Playfulnes; (5) Efficiency berpengaruh negatif dan tidak signifikan terhadap Customer Satisfaction; (6) Service Excellence berpengaruh positif dan signifikan terhadap Customer Satisfaction; (7) Aesthetic berpengaruh negatif dan tidak signifikan Customer Satisfaction; (8) Playfulnes berpengaruh positif dan signifikan terhadap Customer Satisfaction

Berdasarkan hasil penelitian maka saran yang dapat diberikan adalah sebagai berikut, dari kedelapan hipotesis yang diajukan terbukti bahwa Efficiency tidak berpengaruh terhadap Customer Satisfaction oleh karena itu pihak perusahaan haruslah mampu untuk menyediakan pelayanan serta penataan toko yang memudahkan konsumen dari saat konsumen datang, memilih produk sampai pada proses akhir yaitu pembayaran, hal tersebut patut dilakukan agar konsumen merasa waktu yang digunakan untuk berbelanja tidaklah sia-sia. Serta perlu kiranya untuk memperhatikan design ruangan, pemakaian warna, penataan letak merchdanise serta suasana dalam dan luar ruangan, walaupun Matahari Department store memiliki stdanar sendiri yang diterapkan oleh seluruh cabangnya, namun perlu kiranya untuk memberikan sentuhan khusus di tiap cabang agar terkesan unik dan menarik sehingga diharapkan akan memperkuat pengalaman berbelanja yang dirasakan oleh konsumen. 


\section{Daftar Pustaka}

Agusty, F. (2006). Metode Penelitian Manajemen: Pedoman Penelitian Untuk Penulisan Skripsi. Tesis Dan Disertasi Ilmu Manajemen.

Ali, F. \& Amin, M. (2014). The influence of physical environment on emotions, Customer Satisfaction dan behavioural intentions in Chinese resort hotel industry. Journal for Global Business Advancement, 7, 249-266.

Amalia, C. H. (2010). Hubungan antara Kepuasan Konsumen dan Kualitas Pelayanan dengan Loyalitas Konsumen pada Ritel Modern. Universitas Sebelas Maret.

Astari, W. F. \& Pramudana, K. A. S. (2016). Peran Experiential Value Dalam Memediasi Pengaruh Experiential Marketing Terhadap Repurchase Intention. Matrik: Jurnal Manajemen, Strategi Bisnis dan Kewirausahaan, 10.

Baker, J., Parasuraman, A., Grewal, D. \& Voss, G. B. (2002). The influence of multiple store environment cues on perceived merchdanise value dan patronage intentions. Journal of marketing, 66, 120-141.

Chen, Y.-K. \& Hsieh, T. (2010). A study of the relationship among experiential marketing, experiential value dan Customer Satisfaction. Journal of Statistics dan Management Systems, 13, 1283-1303.

Cox, A. D., Cox, D. \& Danerson, R. D. (2005). Reassessing the pleasures of store shopping. Journal of Business research, 58, 250-259.

Dennis, C., King, T., Fiore, A. M. \& Kim, J. (2007). An integrative framework capturing experiential dan utilitarian shopping experience. International Journal of Retail \& Distribution Management, 35, 421-442.

Fitzsimmons, J. \& Fitzsimmons, M. (2013). Service management: Operations, strategy, information technology, McGraw-Hill Higher Education.

Ghozali, I. (2008). Generalized structured component analysis (GSCA) model persamaan struktural berbasis komponen. Badan Penerbit Universitas Diponegoro, Semarang.

Gibson, H. (2005). Towards an understdaning of 'why sport tourists do what they do'. Sport in Society, 8, 198-217.

Hag, S. A. I., Kodir, D, A. \& Priyono, A. A. (2016). Pengaruh Shopping Lifestyle dan Fashion Involvement Terhadap Impulse Buying Behavior. Jurnal Warta Ekonomi, 4.

Haryati, S. \& Tjendrowaseno, T. I. (2012). Rancang Bangun Sistem Informasi E-Commerce Untuk Usaha Fashion Studi Kasus Omah Mode Kudus. Speed-Sentra Penelitian Engineering dan Edukasi, 3.

Hartanto, A. (2017). Laba Bersih Matahari Dept Store Tembus Rp1,3 Miliar : https://tirto.id/laba-bersih-matahari-dept-store-tembus-rp13-miliar-ctFV. Diakses pada 21 Oktober 2017.

Heskett, J. L., Jones, T. O., Loveman, G. W., Sasser, W. E. \& Schlesinger, L. A. (2008). Putting the service-profit chain to work. Harvard business review.

Julian, C. C. \& Ramaseshan, B. (1994). The role of customer-contact personnel in the marketing of a retail bank's services. International Journal of Retail \& Distribution Management, 22, 29-34.

Keng, C. J., Huang, T. L., Zheng, L. J. \& Hsu, M. K. (2007). Modeling service encounters dan customer experiential value in retailing. International Journal of Service Industry Management, 18, 349-367.

Kotler, P. \& Armstrong, G. (2012). Prinsip-prinsip pemasaran. Jakarta: Penerbit Erlangga.

Kurnia, N. I. 2013. Compulsive Buying Behavior Pada Konsumen Ritel Format Fashion Store. Kajian Ilmiah Mahasiswa Manajemen, 2.

Kurnawati, A. (2016). Pengaruh Servicescape dan Service Excellence Terhadap Kepuasan Pelanggan (Studi pada Diva Family Karaoke Malang). Jurnal Ilmiah Mahasiswa FEB, 4.

Mathwick, C., Malhotra, N. K. \& Rigdon, E. (2002). The effect of dynamic retail experiences on experiential perceptions of value: an Internet dan catalog comparison. Journal of retailing, 78, 51-60.

Noor, A. (2016). Perlindungan Terhadap Pasar Tradisional Di Tengah Ekspansi Pasar Ritel Modern. Economica, 4, 107-120. 
Petrick, J. F., Morais, D. D. \& Norman, W. C. (2001). An examination of the determinants of entertainment vacationers' intentions to revisit. Journal of Travel Research, 40, 41-48.

Poulsson, S. H. \& Kale, S. H. (2004). The experience economy dan commercial experiences. The Marketing Review, 4, 267-277.

Prabowo, H. S. (2016). Pengaruh Kualitas Produk, Kualitas Layanan dan Customer value terhadap kepuasan konsumen Legend Coffee Malang. SKRIPSI Jurusan ManajemenFakultas Ekonomi UM.

Priansa, D. J. (2016). Pengaruh E-Wom dan Persepsi Nilai Terhadap Keputusan Konsumen Untuk Berbelanja Online Di Lazada. Ecodemica, 4, 117-124.

Proyer, R. T. \& Ruch, W. (2011). The virtuousness of adult Playfulness: the relation of Playfulness with strengths of character. Psychology of Well-Being: Theory, Research dan Practice, 1, 1.

Semuel, H. (2006). Ekspektasi Pelanggan dan Aplikasi Bauran Pemasaran Terhadap Loyalitas Toko Moderen Dengan Kepuasan Pelanggan Sebagai Intervening: Studi Kasus pada Hypermarket Carrefour di Surabaya. Jurnal Manajemen Pemasaran, 1.

Shieh, K.-F. \& Ming-Sung, C. (2007). An empirical study of experiential value dan lifestyles dan their effects on satisfaction in adolescents: An example using online gaming. Adolescence, 42, 199.

Sofiyanto, I., Fathoni, A. \& Haryono, A. T. (2016). Pengaruh Lokasi, Tingkat Suku Bunga, Kualitas Pelayanan Terhadap Kepuasan Nasabah Kredit Pemilikan Rumah (Studi Empiris Pada PT. Bank Tabungan Negara (Persero) Cabang Semarang). Journal of Management, 2.

Soliha, E. (2008). Analisis Industri Ritel di Indonesia. Jurnal Bisnis dan Ekonomi, 15.

Sulek, J. M. \& Hensley, R. L. (2004). The relative importance of food, atmosphere, dan fairness of wait the case of a full-service restaurant. Cornell Hotel dan Restaurant Administration Quarterly, 45, 235-247.

Utami, C. W. (2010). Manajemen Ritel_Strategi dan Implementasi Operasional Bisnis Ritel Modern Di Indonesia.

Verhagen, T., Feldberg, F., Van Den Hooff, B., Meents, S. \& Merikivi, J.(2011). Satisfaction with virtual worlds: An integrated model of experiential value. Information \& Management, 48, 201-207.

Veryzer JR, R. W. (1993). Aesthetic Response dan the Influence of Design Principles on Product Preferences. Advances in Consumer research, 20.

Wu, C. H.-J. \& Liang, R.-D. (2009). Effect of experiential value on Customer Satisfaction with service encounters in luxury-hotel restaurants. International Journal of Hospitality Management, 28, 586-593.

Jurnal Manajemen Indonesia 